\title{
A simple ex vivo, biologic ERCP training model for sphincterotomy
}

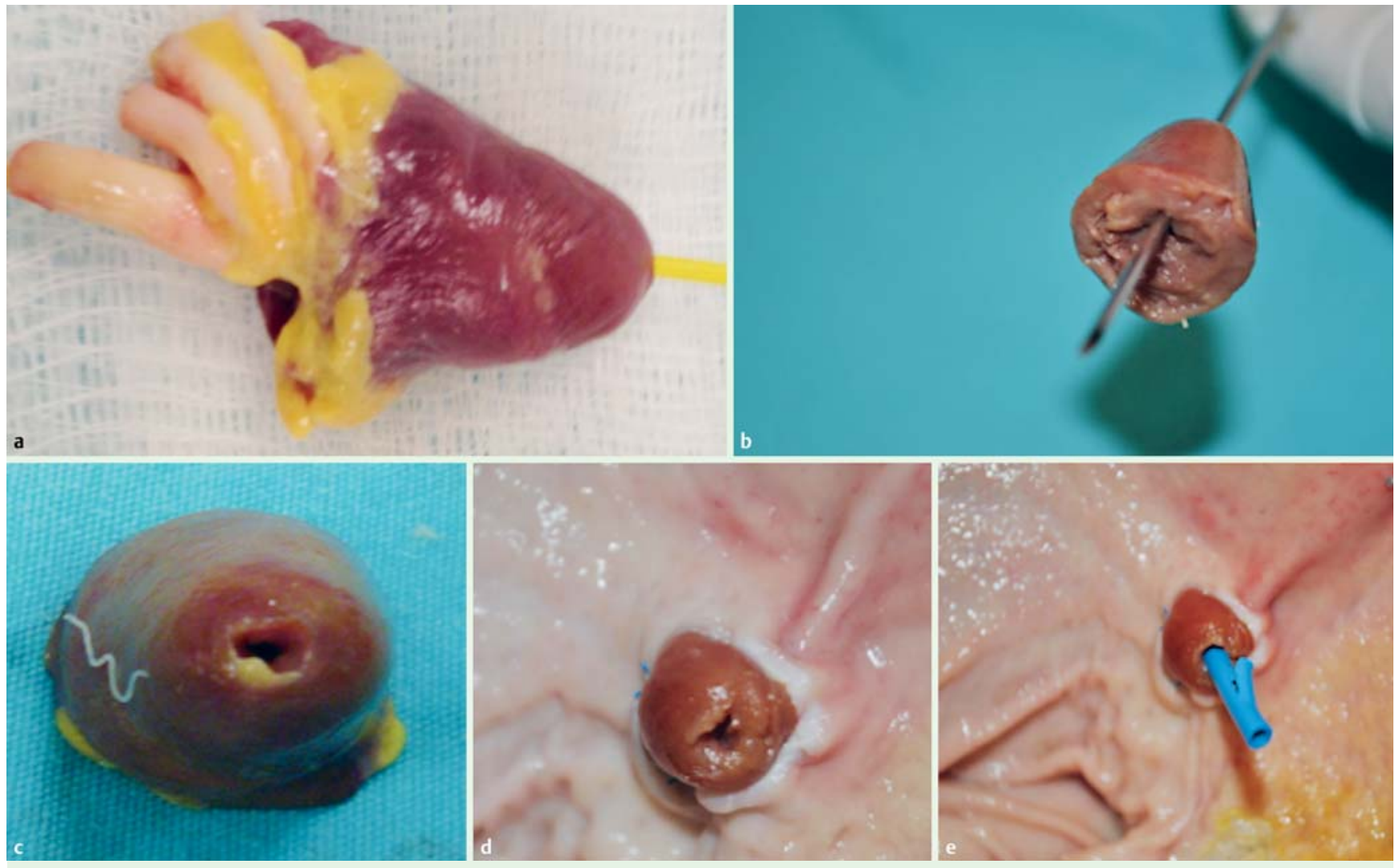

Fig. 1 Chicken hearts serve as ideal models for papillae. Their shape and anatomy resemble true ampullae. a The ventricle and aorta are perfectly suited to create a "bile duct" channel. b The chicken hearts can be cut in half to create smaller "papillae." c The ventricle can be punctured to create a papillary orifice. d An implanted papilla. e Stent inserted into implanted papilla.

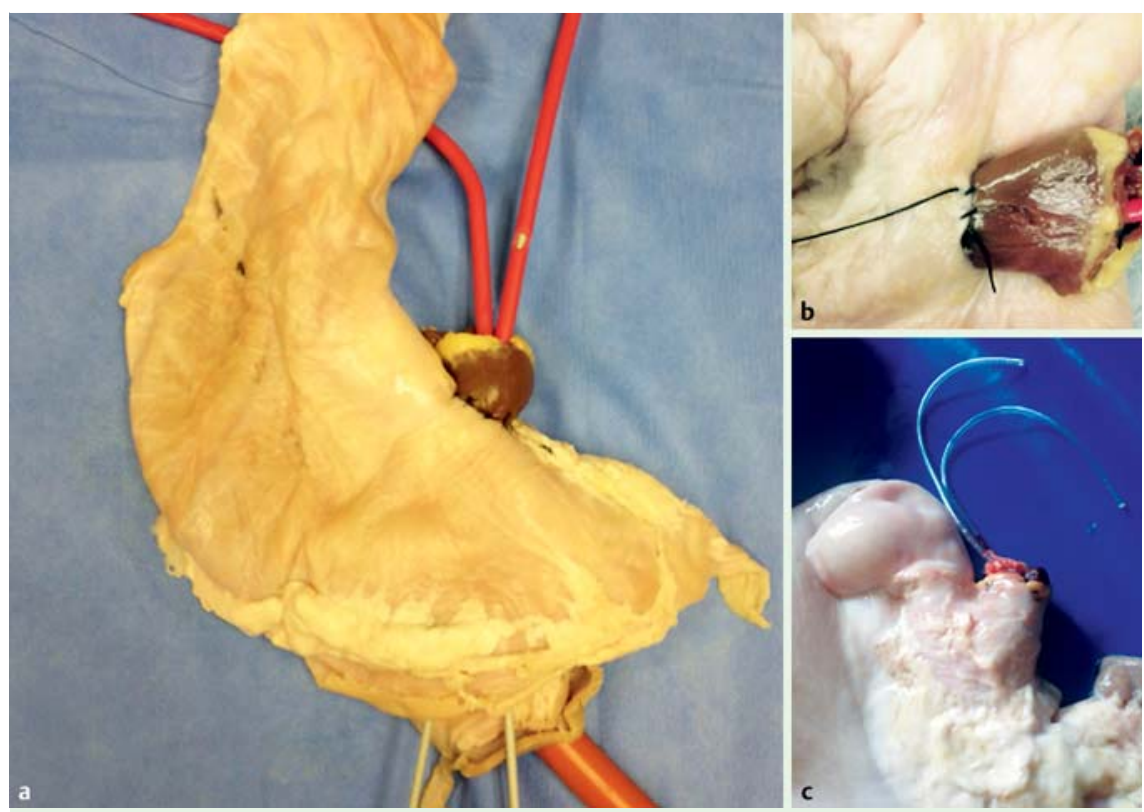

Fig. 2 The "neo-papilla" is attached to a pig stomach using 2-0 silk sutures $(\mathbf{a}-\mathbf{c})$.
The key therapeutic intervention during endoscopic retrograde cholangiopancreatography (ERCP) is sphincterotomy, but lack of training and experience leads to a higher risk of complications [1,2]. Herein, we present a simple, reproducible, easyto-build, ex vivo, ERCP model for the training of sphincterotomy using standard sphincterotomes and a needle knife.

The model is based on incorporating one or more chicken hearts into a pig stomach ( $\bullet$ Fig. 1, $\diamond$ Fig. 2, $\diamond$ Fig. 3, $\diamond$ Video 1). The native pig papilla has some limitations for sphincterotomy training, mainly because of its awkward location in the bulb compared with in the second duodenum in humans. To solve this issue, we previously created a model in which the pig stomach was "duodenalized" to resemble the duodenal sweep in humans [3]. The duodenalization overcame the common position problems when performing ERCP in intact pig stomachs, which are large and J-shaped. In a further development of 


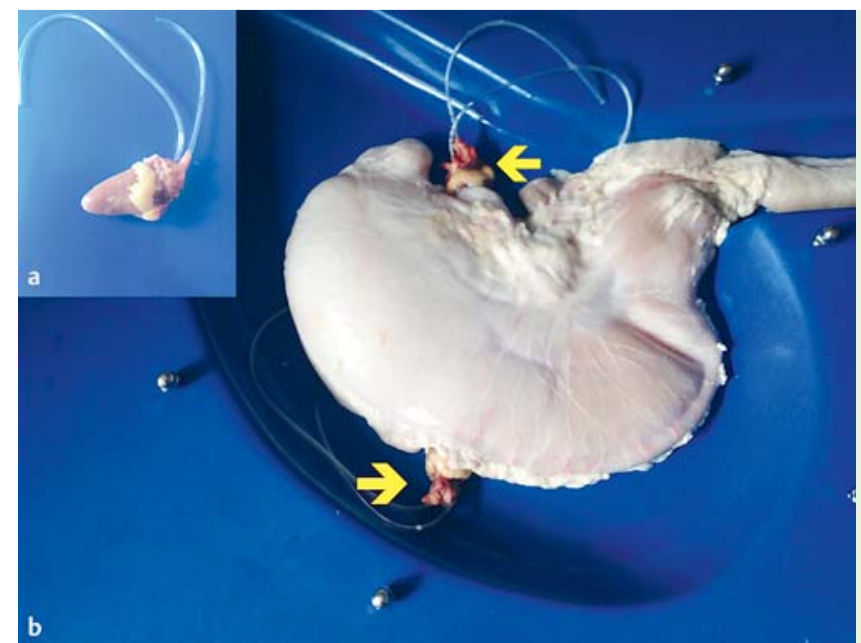

Fig.3 The pig stomach model in a plastic box. a "Neo-papilla" with bile and pancreatic ducts. b Several neopapillae are implanted into different parts of the pig stomach (arrows). This allows the creation of papillae representing various levels of endoscopic difficulty.
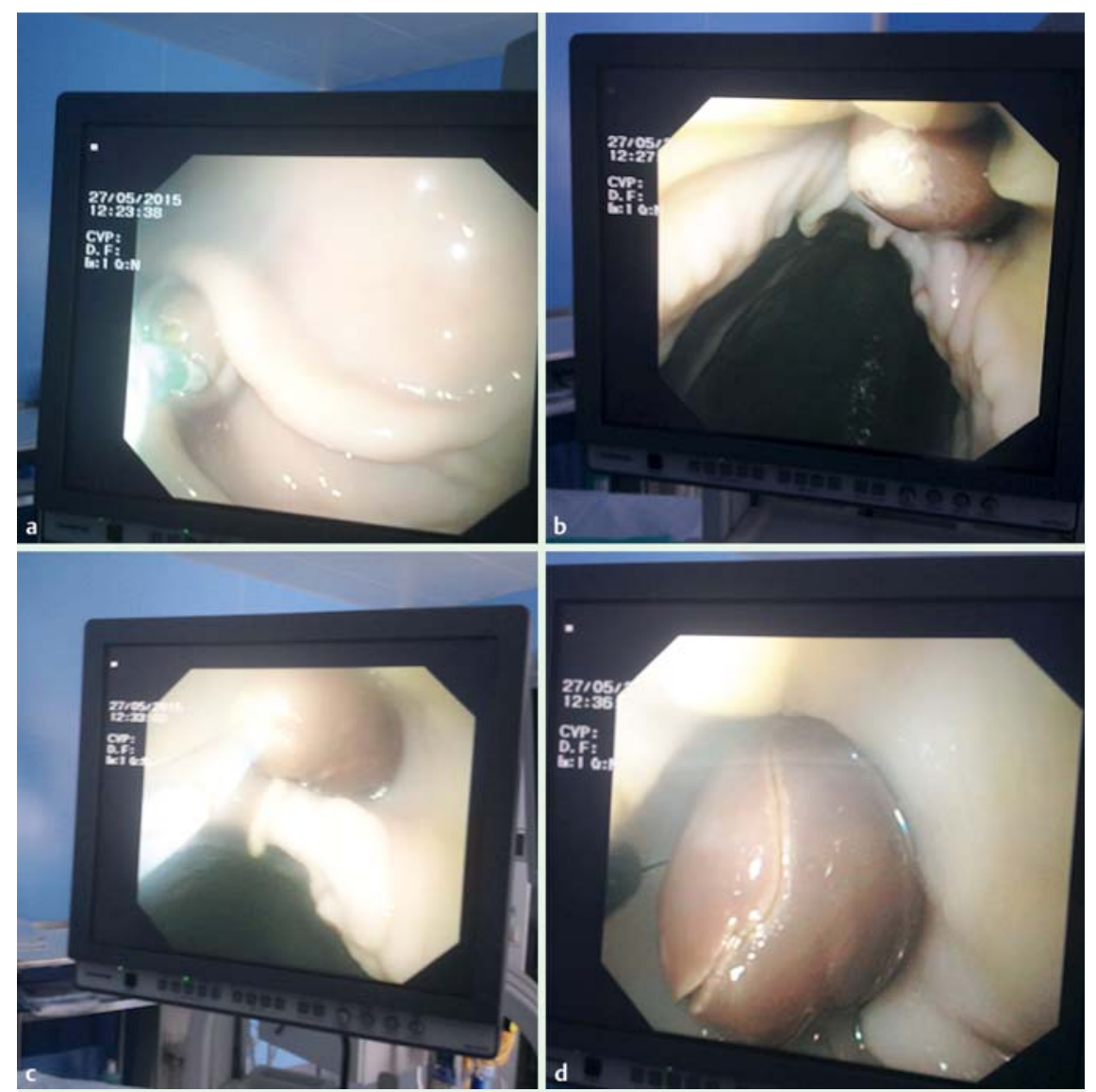

Fig. 4 Endoscopic views. a, b The "papillae." c, d Endoscopic sphincterotomy and precut sphincterotomy.

the model, as presented herein, several papillae were implanted into various parts of an intact stomach, thus permitting the endoscopist to practice sphincterotomy in different positions.

The model is built using four key steps: 1 ) pig stomach, 2) creation of several "neopapillae" using chicken hearts, 3) implantation of papillae into various locations of the stomach, and 4) placement of the ex vivo model in a plastic container ( $\bullet$ Fig. $\mathbf{1}$, ๑ Fig.2, ๑ Fig.3, ๑ Video 1). An essential step in the creation of the papilla opening is insertion of a thick needle through the chicken aorta and puncture of the heart apex ( $\odot$ Fig. 1, $\odot$ Video 1 ). Attachment to the stomach is achieved using $2-0$ silk sutures ( $\bullet$ Fig. 2, $\odot$ Video 1 ). Endoscopic sphincterotomy can then be performed using a pull-type sphincterotome $(\bullet$ Fig. 4 , - Video 1). This is the first report of the feasibility of performing realistic precut needle-knife sphincterotomy in an ex vivo ERCP model.

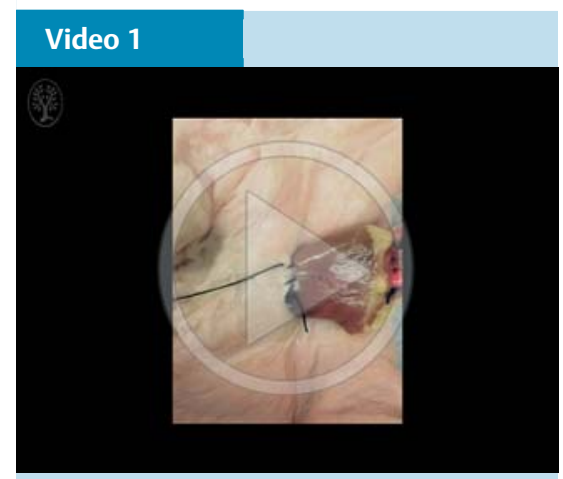

Ex vivo, biologic training model for sphincterotomy during endoscopic retrograde cholangiopancreatography, using a pig stomach with implanted chicken hearts to resemble papillae.

In summary, this model is novel and useful for various reasons. First, it can be reproduced with ease, as the animal visceral parts are easily obtainable. Second, it is inexpensive, enabling endoscopists in any part of the world to reproduce and use the model for training. Third, the papilla has a natural appearance, with strong resemblance to a "real-life" clinical scenario, and cutting the tissue allows the endoscopist to gain experience in the various types of currents used for sphincterotomy. In addition, there is no better replacement for cutting on real tissue when learning a delicate technique such as sphincterotomy. We believe that, for ethical reasons, endoscopists engaging in therapeutic interventions should first obtain experience in ex vivo models before performing the procedure in humans [4]. Finally, to the best of our knowledge, this is the first report of performing precut sphincterotomy in an ex vivo ERCP model.

\section{Endoscopy_UCTN_Code_TTT_1AR_2AC}

\section{Competing interests: None}

Nadan Rustemovic ${ }^{1}$, Marco D’Assuncao $^{2}$, Branko Bilic ${ }^{1}$, Hrovje Ivekovic ${ }^{1}$, Benjamin A. Hewitt ${ }^{3}$, Ivan Jovanovic ${ }^{3}$, Klaus Mönkemüller ${ }^{3}$

\section{${ }^{1}$ Department of Gastroenterology,} University Hospital Center Zagreb, Medical School of Zagreb, Croatia 2 Division of Endoscopy, Department of Surgery, Hospital Sirio Libanes, Sao Paulo, Brazil

3 Basil I. Hirschowitz Endoscopic Center of Excellence, Unit for Experimental Endoscopy and Advanced Endoscopy Training, Division of Gastroenterology and Hepatology, University of Alabama at Birmingham, Alabama, USA 


\section{Acknowledgments}

An American Society for Gastrointestinal Endoscopy (ASGE) research grant supported this work. Klaus Mönkemüller, MD, PhD, FASGE, is the 2014 recipient of an ASGE Research Award. Ivan Jovanovic, MD, PhD, FASGE, is a 2015 Fulbright Scholar and Visiting Professor at the University of Alabama at Birmingham, USA. This work was partially done during Professor Jovanovic's award period at the Basil I. Hirschowitz Endoscopic Center of Excellence, University of Alabama, Birmingham, Alabama, USA.

\section{References}

1 Williams EJ, Taylor S, Fairclough P et al. BSG Audit of ERCP. Are we meeting the standards set for endoscopy? Results of a large-scale prospective survey of endoscopic retrograde cholangio-pancreatograph practice. Gut 2007; 56: 821 - 829

2 Kachaamy TA, Faigel DO. Improving ERCP quality and decreasing risk to patients and providers. Expert Rev Gastroenterol Hepatol 2013; 7: $531-540$

3 Velázquez-Aviña J, Sobrino-Cossío S, ChávezVargas $C$ et al. Development of a novel and simple ex vivo biologic ERCP training model. Gastrointest Endosc 2014; 80: 1161-1167

4 Parra-Blanco A, González N, González R et al. Animal models for endoscopic training: do we really need them? Endoscopy 2013; 45: $478-484$

\section{Bibliography}

DOI http://dx.doi.org/

10.1055/s-0034-1392634

Endoscopy 2015; 47: E401-E403

(C) Georg Thieme Verlag KG

Stuttgart · New York

ISSN 0013-726X

\section{Corresponding author}

\section{Klaus Mönkemüller, MD, PhD, FASGE}

Division of Gastroenterology and Hepatology Basil I. Hirschowitz Endoscopic

Center of Excellence

Endoscopy Unit, JT 664

619 19th Street $S$

Birmingham, AL 35249

USA

Phone: +1-205-934-1240

klaus1@uab.edu 